\title{
MEMÓRIAS DAS ESCOLAS NORMAIS DE CASCAVEL-PR: desafios à preservação
}

\author{
André Paulo Castanha ${ }^{1}$ \\ Jehnny Zélia Kalb Facchi ${ }^{2}$
}

\section{RESUMO}

A discussão proposta neste artigo refere-se ao desafio de preservar arquivos e fontes históricas das escolas normais criadas a partir da Lei Orgânica do ensino Normal, DecretoLei n. 8530, de 2 de janeiro de 1946, especialmente das escolas "Carola Moreira" e "Irene Rickli”, que funcionaram em Cascavel - PR, entre as décadas de 1950 a 1970, cujo intuito é resgatar a história da formação de professores. Parte-se do pressuposto de que uma pesquisa histórica pautada em dados reais e concretos necessita, antes de tudo, que as fontes históricas existam, que estejam preservadas a fim de atuar como testemunhas do passado. Neste sentido, é imprescindível realizar ações no sentido de levantar, catalogar, digitalizar e interpretar todas as fontes possíveis sejam orais, escritas, legais, ou iconográficas num esforço de compreender como era o funcionamento, a prática e organização dessas instituições escolares.

Palavras-chave: Formação de Professores, Escolas Normais, Fontes Históricas, Arquivos Escolares.

\section{NORMAL SCHOOLS' MEMORIES FROM CASCAVEL-PR: challenges to the preservation}

\begin{abstract}
The discussion proposed in this article refers to the challenge of preserving archives and historical sources of normal schools created from the Normal teaching's Organic Law, Decree-Law no. 8530, of January 2, 1946, especially in schools "Carola Moreira" and "Irene Rickli," which worked in Cascavel - PR, between the decades from 1950 to 1970, which purpose is to rescue the teacher education's history. It starts from the assumption that historical research based on real data and concrete needs, first of all, that there are historical sources, which are preserved in order to act as past's witnesses. In this respect, it is essential to carry out actions to raise, catalog, digitize and interpret all possible sources whether oral, written, legal, or iconographic in an effort to understand how was the functioning, practice and organization of these schools.

Keywords: Teacher Education, Normal Schools, Historical Sources, School Files.
\end{abstract}

\section{Introdução}

Se a educação é o conjunto de processos intencionais e não intencionais que forma o indivíduo social, então interrogar-se sobre como ele se forma torna-se uma pergunta múltipla e ilimitada. (Ragazzini, 1999, p. 32).

Nosso objetivo com o presente texto é discutir a problemática da preservação da memória histórica das instituições escolares, neste caso, mais especificamente, sobre a 
preservação das fontes referentes à Escola Normal Ginasial Carola Moreira e Escola Normal Colegial Irene Rickli, que formaram professores nas décadas de 1960 e 1970, no município de Cascavel e região.

A fundação dessas instituições seguiu as orientações da Lei Orgânica do Ensino Normal instituída pelo Decreto-Lei n. 8.530, de 2 de janeiro de 1946 e da Lei n. 4.024, a LDB de 1961. Já a extinção/incorporação das mesmas instituições se deu a partir da aprovação da Lei 5.692/71, a LDB de 1971, que instituiu o antigo magistério profissionalizante de $2^{\circ}$ grau.

Quais os fatores políticos, econômicos, sociais e culturais que determinaram a criação das escolas normais em Cascavel? Quais suas formas de organização? Como a Lei Orgância para o Ensino Normal se materializou concretamente na realidade dessas escolas? Estas são questões cujas respostas apenas serão possíveis a partir de pesquisas fundamentadas nos arquivos e nas fontes produzidas ao longo da história por ambas as escolas. Não temos, neste texto, a pretensão de respondê-las, apenas de apontar alguns caminhos e mostrar onde estão algumas fontes e as condições de preservação das mesmas. Tais questões serão (ou poderão ser) respondidas num futuro texto.

Nos arquivos indicados no decorrer do texto, estão documentos que expressam a história dessas duas instituições escolares, que já não existem mais, porém, no período de existência desempenharam um papel social possível de ser resgatado e compreendido. Segundo Magalhães:

A história das instituições educativas constitui um processo epistêmico que medeia entre a(s) memória(s) e o arquivo, não se limitando a memória às dimensões orais, mas incluindo as crônicas e outros textos afins e não se confinando o arquivo à documentação e informação escritas. (1999, p. 69).

Assim, para compreendermos o papel histórico dessas instituições, para Cascavel e região, precisamos levantar, catalogar e interpretar as fontes, sejam elas: escritas, iconográficas, imagéticas, orais, legais ou os estudos que já foram produzidos sobre o tema. Sabemos que fontes existem, o problema é localizá-las e principalmente preservá-las. Mas, esse é um desafio que precisamos enfrentar.

Para tanto, organizamos o texto da seguinte forma: inicialmente fizemos algumas considerações sobre o uso das fontes nos estudos sobre instituições escolares, a partir de autores referências no campo da História da Educação; em seguida indicamos as bases legais, em âmbito nacional, que estimularam a criação das referidas instituições; no tópico seguinte procuramos trazer alguns dados históricos sobre a criação e funcionamento das escolas normais Carola Moreira e Irene Rickli; feito isso, passamos a tratar dos arquivos onde estão alocados documentos sobre as escolas normais, condições e desafios à preservação, indicando alguns procedimentos que vem sendo adotados para preservar as fontes; por fim fazemos algumas considerações finais.

\section{O Uso das Fontes na Construção e/ou Reconstrução da História das Instituições Educativas}

Nos últimos anos as pesquisas sobre as instituições escolares ganharam destaque no campo da história da educação e, em consequência disso, contribuíram efetivamente para fortalecer o campo histórico-educativo, frente aos demais campos da educação. Isso se deu, principalmente pela aproximação da historiografia educacional das teorias da história, especialmente da corrente da História Nova e suas vertentes: história cultural e micro- 
história.

Guiados por tais teorias, muitos pesquisadores adentraram ao interior das instituições escolares ou educativas produzindo detalhados estudos sobre as relações presentes no cotidiano das instituições, mas, muitas vezes sem estabelecer relações mais amplas com a sociedade. Como nos orienta Ragazzini, "a história das instituições educativas não pode se limitar aos aspectos estritamente normativos", pois as instituições são governadas ou gerenciadas por "decisões políticas, periféricas e centrais"; definidas "por espaços organizados, tempos administrados e modalidades internas de funcionamento"; e constituídas por diversos profissionais, alunos e familiares, os quais estabelecem "relações externas com outras instituições, com os contextos ambientais e a dinâmica social". (1999, p. 26).

Segundo Magalhães, "uma instituição educativa não é estática, nem a percepção de conjunto se obtém a partir de uma única fonte ou de uma só vez" (1999, p. 69). É fato concreto que as instituições educativas "formalmente definidas tornam-se lugares e espaços de determinação social", evidenciando que é "elástico o limite entre instituições educativas e aspectos educativos das instituições". Isso nos leva a pensar as instituições escolares ou educativas como um dos pilares da "história social da educação". (RAGAZZINI, 1999, p. 26). ${ }^{3}$

Para entendermos o papel histórico das instituições educativas temos que vê-las como "uma totalidade em construção e organização", tanto histórica, como pedagógica. Segundo definiu Magalhães a

instituição educativa apresenta uma cultura pedagógica que compreende um ideário e práticas de diversas natureza, dados os fins, os atores, os conteúdos, inserida num contexto histórico e desenvolvendo uma relação educacional adequada aos públicos, aos fins, aos condicionalismos e às circunstâncias (1999, p. 68-9).

Como fazer para captar a totalidade histórica das instituições educativas? Isso só será possível, se, no processo de investigação nos cercarmos de uma diversidade de fontes e soubermos articular devidamente o contexto de produção e os mecanismos de seleção das fontes, a partir de interrogações claras e consistentes que fizermos aos documentos. Ragazzini sustenta que "a fonte provém do passado, é o passado, mas não está mais no passado quando é interrogada". A fonte é "uma ponte, um veículo, uma testemunha, um lugar de verificação, um elemento capaz de propiciar conhecimentos acertados sobre o passado" (2001, p. 14). Porém, para se chegar a um conhecimento acertado é preciso considerar "as relações nas quais nasce e se produz o documento", as relações, que no âmbito dos acontecimentos selecionam, conservam e inventariam os documentos e "as relações do leitor-intérprete com as suas questões e com os destinatários dos seus estudos" (2001, p. 15).

Para desenvolver o trabalho com fontes, é preciso antes de mais nada, periodizá-las, ou seja, selecioná-las a partir de um determinado período, em seguida, compreendê-las a partir do contexto histórico em que foram produzidas. Segundo Ragazzini:

Periodizar, de fato, não é somente encontrar os pontos de início e conclusão, os pontos altos e os baixos do explanandum histórico, mas também os pontos de início e de conclusão, os pontos altos e baixos das variáveis explanantes, individualmente consideradas, mas sobretudo, consideradas nas suas relações recíprocas e com o tema escolhido como objeto historiográfico (1999, p. 32-33). 
Além dos cuidados com as articulações entre contexto, conservação, periodização das fontes, devemos nos preocupar com a qualidade das questões que fazemos a elas. Uma categoria eficiente que pode ser usada no processo de interrogação das fontes é a da contradição. Ela ajuda a olhar para as fontes e observar se elas incorporam conflitos de classes e não apenas puras determinações. É preciso apreender o que determina estruturalmente um documento, ou seja, sua essência. Segundo Evangelista, as fontes muitas vezes "mentem", pois

Há nelas mais do que o dito textualmente. O que a fonte silencia pode ser mais importante do que o que proclama, razão pela qual nosso esforço deve ser o de apreender o que está dito e o que não está. Ler nas entrelinhas parece recomendação supérflua, entretanto deve-se perguntarthe o que oculta e por que oculta: fazer sangrar a fonte (2011, p. 10).

Mas o que são fontes? Segundo Lombardi:

As fontes resultam da ação histórica do homem e, mesmo que não tenham sido produzidas com a intencionalidade de registrar a sua vida e o seu mundo, acabam testemunhando o mundo dos homens em suas relações com outros homens e com o mundo circundante, a natureza, de forma que produza e reproduza as condições de existência e de vida (2004, p. 155).

Em outras palavras: as fontes foram e são produzidas pelas ações dos homens, que, ao produzirem e reproduzirem sua vida produzem a história. Nesse processo, foram e estão sendo deixados vestígios e registros que não foram ou são feitos pensando no futuro, mas na e para a sociedade que a produziu ou produz.

As fontes históricas-educativas podem ser encontradas em: arquivos públicos e privados, bibliotecas públicas e privadas, museus públicos e privados, nas instituições educativas, jornais etc., e mediante a realização de entrevistas com pessoas que vivenciaram e vivenciam o cotidiano das instituições. Quanto ao tipo de fontes, Rodríguez classifica da seguinte forma:

1) Fontes escritas: realizadas sobre material duro ou em pedra; também sobre material brando (papiro, pergaminho ou papel, códices ou documentos soltos); ou fontes impressas (crônicas, históricas, coleções de documentos, edições críticas de manuscritos). 2) Fontes materiais: aqueles vestígios que não são documentos, tais como utensílios, móveis, vestimentas, fósseis, pinturas, construções, monumentos, entre outros; 3 ) Fontes orais: são informações e conhecimentos de fatos históricos que se transmitem e se mantêm pela tradição oral, mas que, quando são escritas, se transformam em fontes escritas. [...] 1) Fontes iconográficas: pinturas ou esculturas; 2) Fontes gráficas e imagem: fotografias, postais, ilustrações, gravações, retratos, cinema e televisão; 3) Fontes arqueológicas; 4) Fontes hemerográficas: periódicos, revistas, jornais, boletins, monografias, entre outras; 5) Fontes informatizadas e novas tecnologias (2010, p. 42. Grifos do autor).

E o que podemos dizer sobre os arquivos? Há muitas definições para o conceito, porém, para uma melhor compreensão da realidade, deve-se optar por aquelas que levem em conta as relações dinâmicas e complexas da sociedade que os produziram. Portanto, arquivo não pode ser compreendido apenas como um lugar onde se recolhe e guarda 
documentos, mas primordialmente como fonte que possibilita "a sensação da descoberta do real", na medida em que não mais se examina meras narrativas sobre as coisas, mas sim as próprias coisas em si. (MIGUEL, 2007, p. 31). Segundo Magalhães,

$\mathrm{O}$ arquivo, tal como se encontra organizado, quando o investigador inicia o seu trabalho, constitui uma informação multidimensional e uma representação muito aproximada da evolução, das dimensões e do sentido que a instituição empresta ao seu quotidiano e ao seu destino. $O$ arquivo é uma imagem complexa, mas muito sugestiva, capaz de fornecer ao investigador percepção que constitui uma iluminação sobre a realidade a historiar (1999, p. 70).

De fato, não há dúvidas de que as condições de organização de um arquivo de uma determinada instituição, são reveladoras da importância que a mesma dá a sua memória histórica.

No presente texto temos como objetivo central compreender as escolas normais criadas após 1946, cuja grande maioria delas foram suprimidas ou incorporadas aos cursos de magistério, criados a partir da LDB de 1971. Por se tratarem de instituições de vida efêmera, porém situadas em um período histórico ainda considerado próximo, dois tipos de fontes se apresentam como relevantes, em face da precariedade na organização dos arquivos das instituições, que as abrigaram. Estamos nos referindo ao conjunto da legislação (seja de caráter nacional, estadual ou do interior das instituições) e das fontes orais ainda disponíveis, tanto de ex-professores, quanto de ex-alunos.

Partimos da compreensão de que as leis, em nível mais amplo, são normas que regulam a vida coletiva a partir de alguns preceitos e princípios pautados no modo como os homens produzem sua existência material. Em outras palavras: "toda a legislação traz em si as características da sociedade que a produziu" (CASTANHA, 2011, p. 315). Portanto, para proceder à análise de uma legislação, não se pode de forma alguma, desvinculá-la do contexto em que foram formuladas, contexto esse, repleto de homens e mulheres reais, de carne e osso, que organizam sua vida material e espiritual a partir de determinadas condições.

Quanto ao uso das fontes orais concordamos com Werle ao enfatizar que à "história das instituições escolares muito contribuem os relatos orais, cuja base é a memória. Narrativas orais, realizadas por meio de entrevistas, são momentos de encontro, escuta, troca em que a memória desempenha papel importante" (2004, p. 26). Todavia, a utilização desse tipo de fonte exige do pesquisador uma série de cuidados, tanto na coleta, quanto na interpretação. Conforme destacam Lopes e Galvão "a utilização da história oral, muitas vezes considerada simples pelos pesquisadores, propõe, na verdade, uma série de problemas". Entre eles destacam-se "a imprevisibilidade e o não-controle da situação, o que requer do pesquisador a disposição e a habilidade para a escuta". Ao interpretar as informações colhidas "é necessário relativizar as respostas dadas pelos entrevistados", pois, sabemos "que a memória é seletiva, que os depoimentos mudam no decorrer do tempo, que muitas vezes os entrevistados falam o que imaginam que devem falar para aquele interlocutor específico, sobre o qual criam certas expectativas e ao qual atribuem determinados valores" (2001, p. 89).

Cientes da responsabilidade e também dos limites, adotamos os pressupostos acima para investigar os arquivos das escolas normais Carlota Moreira e Irene Rickli, a fim de compreender o papel histórico de tais instituições, em Cascavel e na região Oeste do Paraná, entre as décadas de 1950 e 1970. 


\section{A Legislação Educacional e a Organização das Escolas Normais}

O problema da formação de professores se constituiu e ainda se constitui, num dos entraves para o franco desenvolvimento da educação nacional, todavia, a história tem mostrado significativos avanços nesse campo. Antes da Lei Orgânica do Ensino Normal, expedida pelo Decreto-Lei n. 8.530, de dois de janeiro de 1946, as escolas normais, até então existentes, resultaram de experiências desenvolvidas pelas províncias ou estados, cujas diretrizes mudavam frequentemente, devido à instabilidade política e a falta de investimento efetivo na formação de professores.

$\mathrm{Na}$ década de 1930, o Brasil passou por uma ampla reorganização política e econômica, primeiramente, com a assim denominada "Revolução de 1930", a qual colocou Getúlio Vargas no comando da Nação, mediante o apoio das elites urbanas e dos movimentos organizados dos trabalhadores. O governo Vargas, de perfil nacionalista era avesso a democracia e as críticas dos opositores. Alegando combater os opositores, especialmente o "perigo do comunismo", Vargas e seus aliados arquitetaram o golpe de Estado de 1937, instituindo o período definido como o "Estado Novo", promulgando uma nova Constituição - a Constituição de 1937.

Todas as mudanças instituídas na vida social, política e econômica, fizeram com que surgisse a necessidade de reformulações também no campo educacional. Nada de transformações radicais, mas sim, "reformas" capazes de auxiliar no desenvolvimento da nova ordem que se pretendia instaurar. Segundo Mészáros,

[...] os processos educacionais e os processos sociais mais abrangentes de reprodução estão intimamente ligados. Consequentemente, uma reformulação significativa da educação é inconcebível sem a correspondente transformação do quadro social no qual as práticas educacionais da sociedade devem cumprir as suas vitais e historicamente importantes funções de mudança (2005, p. 25).

Vargas conseguiu cooptar para o seu governo, vários intelectuais de referência em diversos setores da vida política, econômica, social e cultural do país. No campo da educação destacou-se, o ministro Gustavo Capanema, que assumiu o Ministério da Educação, ainda em 1934. Capanema seguiu as diretrizes de Francisco Campus, primeiro ministro da educação da era Vargas. A partir do início da década de 1940, Getúlio Vargas e Gustavo Capanema baixaram, via decretos-leis, as chamadas leis orgânicas de alguns setores da educação nacional ${ }^{4}$.

No final de outubro de 1945, Getúlio Vargas e seus ministros foram depostos do governo pelos militares, todavia a lógica centralizadora persistiu no campo da educação, pois, o governo provisório de José Linhares manteve a prática dos decretos-leis e das leis orgânicas ao expedir, em 2 de janeiro de 1946 os decretos n. 8.529 - Lei Orgânica do Ensino Primário e o de n. 8.530 - Lei Orgânica do Ensino Normal, objetivando dar uma nova organização, de caráter nacional, a esses dois ramos do ensino. A Lei Orgânica do Ensino Normal foi, portanto, elaborada no período em que estava instaurado o "Estado Novo", cujas características diziam respeito a um regime político de caráter centralizador e autoritário conduzido por Getúlio Vargas, porém sua outorga se deu em 1946, momento em que se iniciava um período de redemocratização no país ${ }^{5}$.

O caráter nacional e impositivo ficou explícito, dias depois, quando o mesmo governo Linhares baixou, em 8 de janeiro, o Decreto-Lei n. 8.586, que determinou o seguinte: 
Art. $1^{\circ}$ Os Estados, os Territórios e o Distrito Federal deverão adaptar os seus respectivos sistemas de ensino normal aos princípios e normas que estabelece o Decreto-lei no 8.530, de 2 de janeiro de 1946 (Lei Orgânica do Ensino Normal) até 31 de agosto do corrente ano para integral vigência no ano letivo seguinte.

Art. $2^{\circ}$ As bases os programas de ensino normal de que trata o art. 13 da lei orgânica referida no artigo anterior serão expedidas pelo Ministro da Educação e Saúde, até a mesma data. (BRASIL. Decreto-Lei n. 8.586, de 1946) ${ }^{6}$.

Tais leis não estavam desvinculadas da realidade, mas constituíram-se como expressões e sínteses dos conflitos e tensões sociais. Em outras palavras, foram manifestações normativas referentes à organização social, que se apresentaram, não como resultado de vontades individuais ou de uma única classe, mas como resultado possível de um determinado momento histórico, levando em conta diferentes anseios e necessidades. A lei expressa, na verdade, uma síntese de múltiplas determinações, por isso entendemos que:

Enquanto na democracia, as leis são resultado de debates travados na sociedade e no parlamento, nos governos despóticos e ditatoriais, as leis são impostas de cima para baixo. Todavia, o fato de as leis serem impostas, não miniminiza o seu caráter de síntese, visto que a imposição de ações mais duras, geralmente, justifica-se pelo aumento de resistência ou por pressão de determinados setores da sociedade" (CASTANHA, 2011, p. 317).

Ao serem modificadas as relações sociais, a educação necessariamente também precisa ser alterada a fim de atender as novas exigências da sociedade. Nesse processo, a legislação educacional, como resultado do embate entre diferentes interesses de classes, passa a ter um importante papel de regulamentação e normatização de toda sua estrutura.

As leis educacionais foram e são recebidas, interpretadas e implementadas de maneiras diferenciadas, ou seja, cada instituição de ensino, a partir de suas especificidades, assimila as leis de acordo com as condições objetivas que lhe são pertinentes. Assim, por exemplo, a Lei Orgânica do Ensino Normal de 1946, não foi aplicada exatamente da mesma forma em todas as escolas normais do país. Embora o que se almejava fosse uma padronização na formação docente, as condições materiais de cada realidade, ora contribuíram para que a legislação fosse implementada a contento, ora proporcionaram falhas na sua implantação, pois faltava professores habilitados para ministrarem as aulas nos cursos normais, estrutura física, pedagógica entre outras. Sobre esse aspecto Tanuri concluiu que "a grande maioria dos estados tomou a referida Lei Orgânica como modelo para reorganização de suas escolas normais, o que contribuiu para que se consolidasse em todo o país um padrão semelhante de formação, ainda que diversificado em dois níveis de escolas" (2000, p. 77).

As principais medidas instituídas pela Lei Orgânica do Ensino Normal foram as seguintes: o artigo $1^{\mathrm{o}}$ da Lei definiu três finalidades claras e objetivas: a $1^{\mathrm{a}}$ referia-se a uma necessidade básica que era "prover à formação do pessoal docente necessário às escolas primárias", visto que em todo país havia carência de professores, principalmente habilitados; a $2^{\mathrm{a}}$ estabelecia a necessidade de "habilitar administradores escolares destinados às mesmas escolas" e, a $3^{\text {a }}$ preconizava "desenvolver e propagar os conhecimentos e técnicas relativas à educação da infância" (BRASIL, Decreto-Lei n. 8530, de 1946).

O ensino normal foi organizado em dois ciclos. O primeiro ciclo era de nível

Revista HISTEDBR On-line, Campinas, número especial, p. 162-180, mai2012 - ISSN: 1676-2584 168 
ginasial, com duração de quatro anos e formava o regente de ensino primário, sendo ofertado apenas por estabelecimentos denominados como Curso Normal Regional. No caso de Cascavel, correspondeu à Escola Normal Regional Carola Moreira. O segundo ciclo era de nível colegial, com duração de três anos formava o professor de ensino primário, sendo ofertado por Escolas Normais. No caso de Cascavel, correspondeu à Escola Normal Colegial Irene Rickli. Além desses, havia também o Instituto de Educação, estabelecimento destinado a habilitar administradores escolares do grau primário. Os Institutos também poderiam ofertar os dois ciclos mencionados ${ }^{7}$.

$\mathrm{O}$ artigo 47 determinava que todos os estabelecimentos de ensino normal deveriam manter "escolas primárias anexas para demonstração e prática de ensino"; o curso normal regional deveria manter, "pelo menos, duas escolas primárias isoladas". A escola normal colegial deveria manter "um grupo escolar"; e os institutos de educação manteriam "um grupo escolar e um jardim de infância" (BRASIL. Decreto-Lei n. 8530, de 1946). Essa imposição legal pode explicar a existência dos complexos escolares formados por várias escolas, nas décadas de 1960 e 1970.

Em setembro de 1946 foi promulgada a nova constituição nacional, a qual dava poderes ao governo federal de estabelecer as diretrizes e bases da educação nacional. Para cumprir tal dispositivo, o governo Dutra nomeou uma comissão de especialistas para elaborarem um projeto de LDB. O projeto foi entregue à Câmara dos Deputados em 1948. Depois de várias emendas e de projetos substitutivos, a LDB foi aprovada em 1961, pela Lei n. 4.024, mas promulgada definitivamente, somente em 14 de dezembro de 1962. A política de formação de professores foi definida entre os artigos 52 e 61 . A LDB manteve os mesmos princípios da Lei Orgânica ao estabelecer escolas normais de grau ginasial com duração de quatro anos, para formar professores regentes de escolas primárias; escolas normais colegiais com três séries, para formar os professores primários; e os institutos de educação que formavam, além dos professores primários, também os especialistas. (BRASIL. Lei n. 4024, de 1961, p. 68-9).

A Lei 5.692 de 1971 fixou as diretrizes e bases da educação nacional para o $1^{\circ}$ e $2^{\circ}$ graus. A problemática da formação dos professores foi tratada entre os artigos 29 e 40 . A LDB estabeleceu a formação em nível de $2^{\circ}$ grau - magistério de $2^{\circ}$ grau, para os professores de $1^{\mathrm{a}}$ a $4^{\mathrm{a}}$ séries; formação em nível superior - licenciatura curta, para professores de $1^{\mathrm{a}}$ a $8^{\mathrm{a}}$ série; e formação em nível superior - licenciatura plena, para professores de $1^{\circ}$ e $2^{\circ}$ graus. (BRASIL. Lei n. 5.692 de 1971, p. 122-24). Ao analisar a LDB de 1971, Tanuri concluiu que, "no bojo da profissionalização obrigatória adotada para o segundo grau", a lei transformou a escola normal "numa das habilitações desse nível de ensino", abolindo a formação em nível ginasial. A tradicional escola normal perdeu seu status, "diluindo-se numa das muitas habilitações profissionais do ensino de segundo grau, a chamada Habilitação Específica para o Magistério (HEM)” (2000, p. 80).

Vimos que tanto a Lei Orgânica do Ensino Normal, de 1946, quanto a LDB de 1961 e 1971 foram elaboradas como diretrizes nacionais, numa tentativa de uniformizar o ensino. Sobre isso cabem os seguintes questionamentos: como tais reformas se configuraram no ensino normal no município de Cascavel? Quais as dificuldades encontradas para cumprir as leis? Que alternativas foram encontradas pela coletividade cascavelense? Os arquivos das instituições escolares que ofertaram esse tipo de ensino guardam fontes históricas que podem ser peças-chave para auxiliar no desenvolvimento da pesquisa. 


\section{Escolas Normais de Cascavel: dos indícios às fontes}

Após a "Revolução de 1930", o Brasil entrou numa nova fase política e econômica. Uma das principais metas do governo Vargas era garantir a "ocupação das fronteiras", os chamados "sertões do Brasil", e com esse objetivo, se incentivou a "marcha para o oeste". Tal política acelerou a ocupação da região Oeste do Paraná, visto que, nas décadas de 1940 e 1950, Cascavel e demais municípios passaram a receber um grande contingente de pessoas, vindas principalmente do Rio Grande do Sul e de Santa Catarina. O rápido aumento da população na região provocou um acelerado crescimento urbano e econômico, acentuando a necessidade de mais escolas de ensino primário e de professores habilitados, para nelas atuarem e atenderem a demanda crescente por instrução.

Ao iniciarmos a pesquisa sobre a formação de professores no município de Cascavel, mais especificamente sobre as escolas normais, percebemos que, praticamente nada havia sido escrito sobre elas nas bibliografias disponíveis. Encontramos um único parágrafo no livro "Pequena história de Cascavel e do Oeste", de Alceu e Carlos Sperança, que informam o seguinte:
A Escola Normal Regional é criada em 1957 sob orientação da Professora Irene Grimbor Rickli, também sua primeira diretora recebendo a designação de Escola Normal Regional Carola Moreira em 1959. Em seus primeiros anos de atividade, a Escola Normal Carola Moreira possuía em seu corpo docente apenas as professoras Cecília Lemos Martins, Genoveva Trindade e Marilda Binder. O educandário em 1963, foi extinto. Reviveu na Escola Normal Secundária Irene Rickli, tendo na direção a Professora Elci Santos de Oliveria, que dedicou muito de seus esfoços para a criação do estabelecimento. A Escola Irene Rickli será em 1974 incorporada ao Complexo Escolar Irene Rickli, do qual também faz parte o Colégio Wilson Joffre (Sperança \& Sperança, 1980, p. 118-119).

Em vista da falta de bibliografias sobre o tema, tornou-se imperativa a necessidade de investigarmos os arquivos atrás de fontes dessas instituições, para podermos confirmar ou refutar as poucas informações que temos sobre as escolas normais. Sobre esse desafio a enfrentar, Werle nos orienta.

Fazer história institucional, portanto, exige revisitar o projeto primitivo, a posição do fundador, aquele que lhe deu paternidade, retomar as formas de organização jurídica e material. A abordagem da dimensão institucional poderá evidenciar o conflito entre o instituído e os processos de institucionalização, os momentos, fases ou períodos em que a instituição tendeu a tornar-se um artefato, com funcionamento independente, destacando-se das propostas fundadoras. O jogo entre o instituído e o instituinte, a totalidade em organização, os processos de estruturação e não apenas o estruturado, esses são os desafios a enfrentar no empenho de compor narrativas referentes à história das instituições escolares. (2004, p. 19).

Sabemos que antes da década de 1950, não havia escolas normais em Cascavel. Os interessados deveriam deslocar-se para outras cidades, o que acabava dificultando a formação dos educadores que aqui atuavam. De acordo com Sbardelotto, apenas em 1951, ano da emancipação de Cascavel, é que foi "criado em Foz do Igraçu o primeiro Curso Normal Regional público [...] que acabou cedendo lugar, posteriormente, à Escola Normal 
Secundária "Iguaçu'” (2009, p. 17). Este foi o único curso de formação de professores da região Oeste do Paraná até 1957 , data provável da criação da primeira escola normal de Cascavel de nível ginasial, ou de primeiro ciclo.

No período, o município de Cascavel teve apenas duas escolas normais. Uma de grau ginasial (Escola Normal Regional Carola Moreira) e outra de grau colegial (Escola Normal Colegial Irene Rickli). Os arquivos com fontes referentes as duas escolas encontram-se no Colégio Estadual Wilson Joffre, que até hoje oferece o curso de Magistério. Após a localização dos arquivos das escolas normais "Carola Moreira" e "Irene Rickli" e, dos documentos contidos neles, procuramos olhar para aquele acervo histórico como um conjunto de evidências, como pistas históricas capazes de possibilitar estudos, investigações e futuras compreensões acerca dessas instituições de ensino, tendo por compromisso contribuir com a ampliação do estudo em História da Educação da região Oeste do Paraná, em especial com a história da formação dos educadores de Cascavel.

Inicialmente, percebemos a necessidade de um levantamento geral dos documentos separando-os por escolas de $1^{\circ}$ e $2^{\circ}$ ciclos (visto que estavam todos juntos), ano em que foram produzidos e tipos de documentos. O levantamento revelou que a maioria das fontes referem-se à documentos burocráticos e administrativos que procuram veicular orientações de funcionamento e organização das escolas como: circulares, ofícios, correspondências, regulamento sobre cobrança de taxas e anuidades e portarias; ou à documentos burocráticos produzidos pelas próprias instituições, como certificados de exames de admissão (contendo notas das avaliações das disciplinas), atas de notas (lista de alunos e suas respectivas notas por disciplina), boletins (contendo dados do aluno, notas, faltas e resultado final), entre outros. Infelizmente, poucos documentos encontrados são de ordem pedagógica, como por exemplo, a lista de bibliografias sugeridas para as disciplinas de Fundamentos da Educação, Introdução aos Estudos Pedagógicos, Filosofia da Educação, Problemas de Educação Brasileira e Paranaense.

Ao iniciar o exame dos documentos, observamos que alguns não estavam datados, outros não apresentavam identificação, se pertenciam à escola Carola Moreira ou à escola Irene Rickli, sem mencionar aqueles documentos escritos em papéis extremamente finos e transparentes, cuja deterioração foi maior em vista da fragilidade, o que nos impossibilitou, até mesmo a simples leitura. Dentre os documentos localizados, alguns nos chamam muito a atenção pelo conteúdo que expressam ou pelas informações sobre as instituições pesquisadas. Ressaltamos a Portaria $n^{\circ} 1.134 / 66$, em que o Secretário da Educação e Cultura do Estado, Lauro Rêgo Barros solicitou que fosse lembrado e comemorado o aniversário de dois anos do chamado

movimento revolucionário de 31 de março de 1964 que devolveu aos lares brasileiros a paz e a tranquilidade tão ameaçadas pela subversão e irresponsbilidade dos que detinham o poder e confiança do povo. Considerando que a nacionalidade muito deve aos líderes civis e militares da revolução restauradora da democracia e às famílias que, com os símbolos de fé entre as mãos, colocaram um fim a tão lastimável estado de coisas. Considerando que é dever desta Secretaria de Estado manter vivo e imperecível o espírito revolucionário de 31 de março nas crianças e jovens estudantes paranaenses - principais beneficiários da renovação imposta, sem sangue e sem ódios, pelos revolucionários de 1964 (PARANÁ. Sec. Ed. e Cultura, Portaria n. 1.134 de 1966).

O documento mencionado mostra-se em perfeita sintonia com os aspectos políticos hegemônicos desse período. Neste sentido, as escolas em geral eram chamadas a 
desempenhar um importante papel de difusão ideológica. Isso ocorria na medida em que a comunidade escolar empenhava-se na organização e apresentação de trabalhos, geralmente ressaltando os aspectos majestosos da pátria, estado ou município numa demonstração patriótica de amor ao país e de apoio a forma com que o mesmo vinha sendo conduzido. Além dos trabalhos, as escolas normais, estavam orientadas a organizar palestras para a comunidade sobre o tema da "Revolução de 1964". Um convite enviado à Escola Normal Regional Carola Moreira pela diretora Elci Santos Oliveira da Escola Normal Colegial Irene Rickli cujo o tema era "A Revolução de 1964", evidencia que o pedido feito pelo Secretário na portaria 1.134/66 foi atendido.

Além dos documentos já citados, as Circulares também compõem o acervo histórico das escolas normais. Entre elas destacamos a Circular no 24, de 1956, em que a Chefe do Ensino Normal, senhora Diva H. Vidal, solicitou que professores e diretores das escolas normais fizessem campanha para aumentar o número de alunos normalistas que era insuficiente estando assim, fora do que era "exigido pela Regulamentação dos Cursos Normais do Estado" e enfatizou a "necessidade que o interior do Estado tem de possuir, professores primários da própria localidade, que além de terem residências fixas, têm por forças dos sentimentos, maior interesse em bem desempenhar sua missão para que seus conterrâneos possam elevar o nível cultural de sua terra" (PARANÁ. SEC, Seção do Ensino Normal, Circular n. 24 de 1956).

Outras Circulares referem-se à necessidade de se constituir o corpo docente com professores normalistas, em concordância com a Regulamentação do Ensino Normal, bem como, a indispensável comprovação de habilitação (diploma ou certificado) dos professores contratados para atuarem nas escolas do ensino normal. Conforme previa uma dessas circulares, cabia ao professor do curso normal:

dar a formação profissional aos seus alunos, deve comparecer, periodicamente aos Cursos de Atualização e Aperfeiçoamento; participar de reuniões pedagógicas em seu estabelecimento, apresentando trabalhos pessoais ou sugestões; colaborar no sentido da elevação do nível cultural de sua Escola, etc. (PARANÁ. SEC. Circular nº 52 de 1959).

Consta ainda no rol de documentos das escolas normais, alguns convites. Dentre eles, destacamos um, em que o Colégio Marista convidou a Diretora da Escola Normal, senhora Genovena Trindade para participar do encerramento do Curso de Aperfeiçoamento de Professores Leigos no dia 28 de julho de 1966. Dados estatísticos, apontam que no ano de 1966 havia um total de 257 professores no município de Cascavel, destes apenas 80 eram normalistas de $1^{\circ}$ ou $2^{\circ}$ ciclo. O restante, 177 não possuiam formação, sendo professores leigos (BRASIL, 1978, p. 664). Vê-se por esses dados que, os Cursos de Aperfeiçoamento de Professores Leigos eram uma necessidade real, pois estes compunham a grande maioria do corpo docente . $^{8}$.

Fica claro, portanto, a necessidade de levantar, catalogar e problematizar os documentos das escolas normais de Cascavel. Essa ação possibilitará reconstruir a história e preservar a memória destas instituições, ressaltando a importância dos cursos normais para aquela sociedade. Conforme afirmou Magalhães:

A construção da história de uma instituição educativa visa, por fim, conferir uma identidade cultural e educacional. Uma interpretação do itinerário histórico, à luz do seu próprio modelo educacional. A história de uma instituição educativa constrói-se a partir de uma investigação coerente e sob um grau de complexificação crescente, pelo que, à 
triangulação entre os historiais anteriores, à memória e ao arquivo, se haverá de contrapor uma representação sintética, orgânica e funcional da instituição - o seu modelo pedagógico. (1999, p, 72).

Eis o desafio que precisamos encarar para avançar nos conhecimentos sobre estas instituições, e, consequentemente, sobre a história da educação local e nacional.

\section{Arquivos das Escolas Normais: os desafios à preservação dos documentos}

Como recuperar e preservar os documentos das instituições que já desapareceram? Quais os locais mais adequados para guardá-los? São questões que precisamos enfrentar, se, de fato, temos como preocupação a preservação da memória histórica.

Como afirmou Werle "um processo de pesquisa que objetive a história de instituições escolares explicita a importância de preservação de documentos para a memória institucional e da sociedade" (2004, p. 31). Cientes disso, passamos a fazer algumas considerações sobre as reais condições em que se encontram os arquivos das escolas normais e a indicar possibilidades para garantir a preservação das fontes que ainda restam.

Constatamos, de modo geral, que os arquivos das escolas normais Carola Moreira e Irene Rickli, infelizmente estão em precárias condições de conservação, pois não há um arquivamento adequado das fontes. Muitas já se perderam, principalmente fotos e documentos de ordem pedagógica. Isso se deu, não por má vontade dos funcionários que trabalham nas instituições que possuem a guarda dos documentos, mas sim pela falta de uma política pública que incentive e garanta a organização dos arquivos públicos e os das instituições escolares.

A maior parte do acervo histórico das escolas normais Carola Moreira e Irene Rickli está sob a guarda do Colégio Estadual Wilson Joffre. Os documentos encontram-se numa salinha próxima à coordenação pedagógica, denominada de "arquivo morto", ou "inativo", ou seja, um local destinado aos documentos que raramente são utilizados. Apesar do espaço ser muito pequeno, felizmente, não constatatamos a existência de goteiras, infiltrações, nem mesmo mofo. Todo o material sobre as escolas normais estão num único armário de aço com três gavetas. Todavia, os documentos não estão organizados, mas apenas depositados em pastas de papelão, ou dentro de envelopes grandes de papel. É preciso extremo cuidado ao manusá-los, pois a maioria deles estão muito frágeis, amarelados e com uma fina camada de poeira de carvão. Funcionários da escola esclareceram que há alguns anos atrás, houve um pequeno incêndio na escola, o qual foi rapidamente controlado pelo corpo de bombeiros. Na época, os documentos ficaram expostos à intensa fumaça formada pelas chamas. Também constatamos que alguns papéis, como relatórios sobre rendimento escolar, são grandes demais para serem acomodados nas pastas de papelão, e, por isso precisam ser dobrados. Tais dobras estão deteriorando os documentos mais rapidamente.

Os documentos que compõem o acervo, basicamente são: boletins, relatórios finais, atas, ofícios, orientações, históricos escolares, grade curricular, correspondências da Inspetoria Regional de Ensino, circulares, portarias, ordem de pagamento, convites, regulamentos, decretos, dados de exames de admissão, atestado de bom comportamento e de integridade física e mental, ordem de serviço, bibliografia básica para as disciplinas do curso normal, listas de alunos. Na instituição, não há um funcionário específico, responsável pelo cuidado e organização do arquivo. Apesar das condições materiais do 
arquivo aqui relatado, percebe-se que os funcionários procuram, dentro das possibilidades, preservar essas fontes históricas.

As pesquisas incluíram também os arquivos do Núcleo Regional de Ensino de Cascavel, onde foram encontradas algumas anotações de decretos feitos à mão. No NRE encontramos os decretos de criação e extinção da Escola Normal Regional Carola Moreira e o decreto de criação da Escola Normal Colegial Irene Rickli, bem como pareceres e resoluções. Esses papéis estão guardados em pastas e bem conservados. Não há nenhum outro tipo de documento arquivado além dos já mencionados, pois como as próprias funcionárias afirmaram, existe a prática de queimar papéis a cada cinco anos, preservandose apenas os contemplados no regulamento, que são basicamente os de ordem legal.

As fontes localizadas no Núcleo Regional de Educação de Cascavel trazem novas informações sobre a vida das escolas normais. Segundo os documentos, a escola Carola Moreira foi fundada pela professora Irene Rickli em 1958, porém, sua implantação ocorreu somente em 1959, autorizada pelo Decreto $n^{\circ} 27.098$, de 21 de dezembro. Sua extinção ocorreu no ano de 1967. Os documentos também revelam que a escola Irene Rickli foi fundada em 1963, pelo Decreto $n^{\circ} 10.909$, de 19 de fevereiro, com base na Lei $n^{\circ} 4.024 / 61$, a LDB de 1961. Diante disso, podemos concluir que as escolas funcionaram concomitantemente, ao menos por quatro anos. ${ }^{9}$

O trabalho de levantamento da documentação sobre as escolas normais inclui também os arquivos da Secretaria Municipal de Educação de Cascavel, da biblioteca pública municipal de Cascavel, do Colégio Estadual Eleodoro Ébano Pereira, da AMOP (Associação dos Municípios do Oeste do Paraná), do MIS - Museu da Imagem e do Som. No acervo da AMOP, praticamente todos os documentos estão numa sala extremamente cheia, tornando-se quase que impossível entrar no ambiente. Além disso, todos os documentos estão dispostos em caixas empilhadas, o que dificulta muito a pesquisa, sendo preciso tirar documento por documento para analisá-los. Apesar disso, os documentos estão em bom estado. Lá encontramos documentos pedagógicos como: apostilas, cartilhas e instruções de uso das cartilhas pelo método Erasmo Pilotto, base das escolas normais do Paraná. Também estão disponíveis documentos denominados de "Diagnóstico e Prognóstico Educacional do Município de Cascavel, Foz do Iguaçu e Toledo referente ao Projeto Especial MEC/OEA (Ministério da Educação e Organização dos Estados Americano), entre outros.

O acervo do MIS, é rico em fotografias. São mais de nove mil fotos. Contudo, elas não estão catalogadas, nem digitalizadas. As condições do local são precárias, pois há infiltrações, os armários são impróprios, não há equipamentos tecnológicos para conservar e digitalizar as fotos. Atualmente, o MIS tem uma parceria com o curso de História da Unioeste - Campos de Marechal Cândido Rondon que está digitalizando as fotos com uma boa resolução. O MIS conta com o trabalho voluntário de moradores antigos de Cascavel para fazer o reconhecimento das fotos (eventos, datas, pessoas). Neste local, foi possível encontrar fotos de desfiles das normalistas e de formatura.

Todas as instituições aqui mencionadas, apesar das condições materiais apresentadas, procuram, dentro das possibilidades, preservarem as fontes históricas. É uma pena que haja por parte das autoridades, pouco comprometimento com a história do município, pois quase nada de investimentos são feitos nessa área.

Temos como objetivo levantar, catalogar e preservar as fontes encontradas nos arquivos, sobre as escolas normais de Cascavel, por isso, a cada visita, procuramos fotografar, ou escanear os documentos levantados, digitalizando e convertendo-os em arquivo $p d f$, a fim de, futuramente disponibilizá-las na internet como um arquivo digital. A tecnologia digital tem sido vista como uma boa alternativa para se preservar e 
disponibilizar documentos históricos ao público, sem comprometer a sua integridade física pelo constante manuseio. A intenção é digitalizar o máximo possível de fontes.

Temos ciência que, mesmo organizando um acervo digital dos documentos históricos, também se faz necessário preservá-los na sua originalidade. Há muito por fazer, mas pode-se iniciar pela higienização e acondicionamento correto dos documentos. Conforme sugerido por Moraes, Zaia e Vendrameto (2005, p. 122), o primeiro passo deve estar relacionado ao levantamento de toda documentação existente, localizando-os dentro e fora da instituição. Em seguida, por meio de oficinas, ensinar técnicas básicas de higienização e acondicionamento aos funcionários responsáveis. Por fim, selecionar um espaço adequado (longe de umidade, mofo e janelas) com armários apropriados para cada tipo de documento. Um último aspecto, diz respeito a denominação desses arquivos, que geralmente são identificados como "arquivo morto", ou "arquivo inativo". Tais termos demonstram falta de compreensão da importância dessas fontes para a pesquisa histórica. Muitos autores propõem que o termo correto seja "arquivo hitórico", ou "arquivo permanente". Silva também destaca que "o desafio consiste em criar as condições objetivas para a preservação das fontes das Instituições Escolares selecionadas, que possibilitem ao historiador a explicitação da singularidade e da identidade histórica das Instituições Escolares" (2008, p. 16).

São necessários investimentos públicos e privados na preservação dos arquivos e fontes. Tais investimentos vão, desde a infraestrutura do prédio como reparos em goteiras e infiltrações, até a aquisição de computadores, scaner, instalação de internet, armários adequados, microfilmagem, enfim, tudo que é indispensável para preservar e tornar acessível às fontes existentes nas Instituições Escolares, bem como nas demais instituições. Ressaltamos também, a conscientização dos funcionários que lidam com tais acervos, pois é comum a prática da eliminação desordenada de documentos, restando em sua maioria, apenas os legais.

Além da preservação das fontes escritas, dos utensílios e objetos escolares, também devemos nos preocupar com os "arquivos vivos", ou seja, as pessoas que carregam uma parte significativa da memória de tais instituições. Hoje ainda é possível encontrar vários ex-professores e ex-alunos que fizeram parte do cotidiano das instituições. Segundo Magalhães:

O quotidiano de uma instituição educativa é um acúmulo de comunicação, tomada de decisões e de participação, cuja representação e memória apenas em parte ficam vertidas a escrito, ou traduzidas noutro tipo de registros, mas boa parte das quais se apagam, quer porque se integram em rotinas, que pela sua frequência não constituem um objeto de registro próprio, quer porque se inserem num processo continuado, tendendo a fixar-se-lhe o princípio e o fim, sendo este, em regra, assinalado por um registro dos resultados. [...] o quotidiano de uma instituição educativa fica representado por defeito, nos registros e fontes de informação, havendo mesmo dimensões desse quotidiano, cuja memória se apaga com a mudança dos atores e muitas outras que são regularmente destruídas. (1999, p. 69).

Localizar, conversar e entrevistar várias dessas pessoas, transformando o diálogo em texto é outra medida que poderemos e devemos tomar para preservar a memória das instituições. A partir do cruzamento das informações obtidas nas entrevistas, com as fontes impressas, a legislação e a bibliografia disponível, poderemos reconstituir a história das instituições com mais confiabilidade histórica. 


\section{Considerações Finais}

Ao analisar alguns documentos dos arquivos das escolas normais existentes em Cascavel, podemos concluir o quão importantes são essas fontes para a pesquisa histórica de uma instituição, pois elas apresentam elementos significativos para a reconstrução histórica, na medida em que nos permitem compreender o seu funcionamento, sua organização, seus avanços e limites, frente à organização social e as leis que regiam a educação nacional. Entretanto, para que seja possível o desenvolvimento de pesquisa histórica, a partir das fontes de época, é preciso que elas sejam minimamente preservadas. Em outras palavras, é preciso que elas existam, para que, posteriormente, possam ser relacionadas "com a história do contexto no qual tais instituições se situam" e "compreendidas à luz das políticas educacionais" do período (Miguel, 2007, p. 34 e 38).

Assim, reforçamos o apelo feito por Saviani quando afirmou:

Penso que já está na hora de desencadear um movimento amplo dirigido às escolas, às organizações da área da educação e aos órgãos do Estado, tendo como mote a questão da política de fontes para a história da educação brasileira. Essa política deverá contemplar os critérios tanto para a definição do que preservar como do que descartar, estabelecendo as metas e os meios que permitirão assegurar a disponibilidade das fontes para o incremento das pesquisas em história da educação brasileira. (2004, p. 11).

Para que isso aconteça, temos que unir esforços cobrando das autoridades públicas, dos gestores das instituições escolares e demais instituições educativas que se preocupem com a memória histórica, criando espaços adequados para a preservação dos documentos. Para, além disso, temos que usar a tecnologia a nosso favor, aproveitando-se do contato direto que temos com as fontes para digitalizá-las, principalmente com o uso das câmaras digitais. Temos que conscientizar as autoridades e gestores de documentos, mas não podemos ficar apenas esperando por eles, precisamos fazer a nossa parte.

Temos clareza que, ao resgatar a história das instituições escolares de ensino normal de Cascavel, contribuiremos para qualificar a leitura da história da educação local e nacional. Não devemos investigar a história das escolas normais apenas para contemplálas, mas, sim, para que esse conhecimento permita uma nova compreensão da realidade, mostrando as implicações na atualidade.

\section{Referências}

BRASIL. Decreto-Lei n. 8.530, de 2 de janeiro de 1946. Lei Orgânica do Ensino Normal. Disponível em: http://www2.camara.gov.br/legin/fed/declei/1940-1949/decreto-lei-8530-2janeiro-1946-458443-publicacaooriginal-1-pe.html. Acessado em: 04 nov. 2011.

BRASIL. Decreto-Lei n. 8.586, de 8 de janeiro de 1946. Dispõe sobre a adaptação dos serviços do ensino normal nos Estados, Territórios e Distrito Federal, à Lei Orgânica do Ensino Normal. Disponível em: http://www2.camara.gov.br/legin/fed/declei/19401949/decreto-lei-8586-8-janeiro-1946-416404-publicacaooriginal-1-pe.html. Acessado em: 04 nov. 2011.

BRASIL. Lei 4.024, de 20 de dezembro de 1961. "Fixa as Diretrizes e Bases da Educação Nacional”. In: DAVIES, Nicholas. Legislação educacional federal básica. São Paulo: Cortez, 2004, p. 45-87.

BRASIL. Lei 5.692. "Fixa diretrizes e bases para o ensino de $1^{\circ}$ e $2^{\circ}$ graus e dá outras 
providências". In: DAVIES, Nicholas. Legislação educacional federal básica. São Paulo: Cortez, 2004, p. 109-134.

CASTANHA, André Paulo. "O uso da legislação educacional como Fonte: orientações a partir do marxismo". In: Revista HISTEDBR On-line, Campinas, número especial, p. 309$331, \mathrm{abr} / 2011$.

EVANGELISTA, Olinda. "Apontamentos para o trabalho com documentos de política educacional". Apostila usada no curso de pós-graduação. s/d, (mineo).

LOMBARDI, José Claudinei. "História e historiografia da educação: atentando para as fontes". In: LOMBARDI, J. C. e NASCIMENTO, M. I. M. (Org). Fontes, História e Historiografia da Educação. Campinas: Autores Associados, 2004, p. 141-176.

LOPES, E. M. T. e GALVÃO, A. M. de O. História da educação. Rio de Janeiro: DP\&A, 2001.

MAGALHÃES, Justino Pereira de. "Breve apontamento para a história das instituições educativas". In: SANFELICE, J. L.; SAVIANI, D.; LOMBARDI, J. C. História da educação: perspectivas para um intercâmbio internacional. Campinas: Autores Associados, 1999, p. 67-72.

MIGUEL, M. E. B. "Os arquivos e fontes como conhecimento da história das instituições escolares". In: SAVIANI, D. e outros. Instituições escolares no Brasil: conceito e reconstrução histórica. Campinas: Autores Associados, 2007, p. 31-38.

MORAES, Carmen Sylvia Vidigal; Zaia, Iomar Barbosa; Vendrameto, Maria Cristina. "Arquivos escolares e pesquisa histórica: fontes para o estudo da educação brasileira". In: Pro-posições. Campinas, SP, v.16, n. 46, jan/abril de 2005, p. 117-133.

PARANÁ. Circular n. 24 - outubro de 1956. Dispõe sobre uma campanha para aumento da matrícula nos cursos normais. Secretaria de Educação e Cultura - Serviço de Ensino Normal. Curitiba, out. 1956. (Arquivo do Colégio Estadual Wilson Joffre, 2011).

Circular n. 52 de 1959. Dispõe sobre a necessidade do corpo docente das Escolas Normais serem constituídas de professores normalistas. Secretaria de Educação e Cultura Serviço de Ensino Normal. Curitiba, 1959. (Arquivo do Colégio Estadual Wilson Joffre, 2011).

Decreto $\mathrm{n}^{\circ}$ 27.098, de 21 de dezembro de 1959. Fundação da Escola Normal Ginasial Carola Moreira, Curitiba. (Arquivo do Núcleo Regional de Ensino de Cascavel, 2011).

Decreto $\mathrm{n}^{\circ}$ 10.909, de 19 de fevereiro de 1963. Fundação da Escola Normal Colegial Irene Rickli Curitiba. (Arquivo do Núcleo Regional de Ensino de Cascavel, 2011).

Portaria n. 1.134 - 9 março de 1966. Dispõe sobre as comemorações do movimento revolucionário de 1964 nas escolas. Curitiba: Secretaria de Educação e Cultura, 1966. (Arquivo do Colégio Estadual Wilson Joffre, 2011).

RAGAZZINI, Dário. "Os estudos histórico-educativos e a história da educação". In: SANFELICE, J. L.; SAVIANI, D.; LOMBARDI, J. C. História da educação: perspectivas para um intercâmbio internacional. Campinas: Autores Associados, 1999, p. 19-35.

"Para quem e o que testemunham as fontes da história da educação?". In: Educar em revista. n. 18/2001. Curitiba: Editora UFPR, 2001 p. 13-28. 
RODRÍGUEZ, Margarita Victoria. "Pesquisa histórica: o trabalho com fontes documentais". In: COSTA, C. J.; MELO, J. J. P. e FABIANO, L. H. Fontes e Métodos em História da Educação. Dourados-MS: Ed. UFGD, 2010, p. 35-48.

SAVIANI, Dermeval. "Breves considerações sobre fontes para a história da educação". In: LOMBARDI, J. C. e NASCIMENTO, M. I. M. (Org). Fontes, História e Historiografia da Educação. Campinas: Autores Associados, 2004, p. 3-12.

. História das idéias pedagógicas no Brasil. $2^{\text {ao }}$ ed. Rev. e ampl. Campinas, SP: Autores Associados, 2008.

SBARDELOTTO, Denise K. O desenvolvimento dos cursos de formação de professores primários na Fronteira Oeste Paranaense: a criação da primeira Escola Normal Secundária Pública de Foz do Iguaçu e do Oeste do paraná. Ponta Grossa, 2009 (Dissertação de mestrado).

SILVA, João Carlos da. "História da Educação: instituições escolares como bjeto de pesquisa”. In: ORSO, P. J.; CASTANHA, A. P. e outros. Educação e História Regional: os desafios de sua reconstrução. Cascavel-PR: Coluna do Saber, 2008, p. 13-25.

SPERANÇA, Alceu A. e SPERANÇA, Carlos. Pequena História de Cascavel e do Oeste. Cascavel, J. S. Impressora, 1980.

TANURI, Leonor Maria. "História da formação de professores". In: Revista Brasileira de Educação, mai/ago 2000, n. 14. Número especial, p. 61-88.

WERLE, Flávia Obino Corrêa. "História das instituições escolares: de que se fala?" In: LOMBARDI, J. C. e NASCIMENTO, M. I. M. (Org). Fontes, História e Historiografia da Educação. Campinas: Autores Associados, 2004, p. 13-35.

XAVIER, Maria E. S. Capitalismo e escola no Brasil: a constituição do liberalismo em ideologia educacional e as reformas do ensino (1931-1961). Campinas: Papirus, 1990.

\section{Notas}

\footnotetext{
${ }^{1}$ Professor do Colegiado de Pedagogia da Unioeste - Campus de Francisco Beltrão e do Mestrado em Educação da Unioeste - Campus de Cascavel. Membro do Grupo de Pesquisa: História, Sociedade e Educação no Brasil - HISTEDOPR. Historiador e mestre em Educação pela UFMT, Doutor em Educação pela UFSCar e Pós-doutor na área de Filosofia e História da Educação pela UNICAMP. E-mail: andrecastanha@brturbo.com.br

${ }^{2}$ Graduada em Pedagogia e Especialista em Fundamentos da Educação pela Unioeste - Campus de Cascavel. Professora da rede municipal de Cascavel e mestranda em Educação na Unioeste, na Linha de Pesquisa em História da Educação. E-mail: facchivel@ hotmail.com

${ }^{3}$ O mesmo Ragazzini acrescenta: "Cada ideia pedagógica deve ser contextualizada no seu tempo. E eis que a história da pedagogia passa pela história das ideologias e das ideologias sociais - ou a leva em conta. Elas, por sua vez, têm sentido se reportadas às sociedades onde nascem e às quais se referem e, em particular, às condições educativas (e a como são compreendidas). Eis que a história da pedagogia se estende à história social da educação (e, ao lado dos Pedagogos com pê maiúsculo, aparecem os educadores do cotidiano)" (1999, p. 25).

${ }^{4}$ No período foram expedidos os seguintes decretos: a) Decreto-lei n. 4.048, de 22 de janeiro de 1942, que criou o SENAI; b) Decreto-lei n. 4.073, de 30 de janeiro de 1942: Lei Orgânica do Ensino Industrial; c) Decreto-lei n. 4.244, de 9 de abril de 1942: Lei Orgânica do Ensino Secundário; d) Decreto-lei n. 6.141, de 18 de dezembro de 1943: Lei Orgânica do Ensino Comercial. (Cf. Saviani, 2008, p. 269).
}

${ }^{5}$ Maria Elizabete Xavier (1990, p. 22) salienta que "as reformas educacionais do período empreendidas por Revista HISTEDBR On-line, Campinas, número especial, p. 162-180, mai2012 - ISSN: 1676-2584 179 
Francisco Campos e Gustavo Capanema, sofreram um julgamento histórico controvertido e preconceituoso", pois, os estudiosos, geralmente apresentam as discussões pedagógicas anteriores à Lei Orgânica como sendo um "avanço progressista" e a própria Lei Orgânica como sendo um "retrocesso conservador". A mesma autora destaca que, a Reforma Capanema não foi o oposto da Reforma Francisco Campos, mas a assimilação do mesmo "discurso educacional liberal com nova roupagem e eficientemente articulado aos interesses dominantes na ordem que se consolidava" (p. 82). Destaca também, que a Reforma Capanema "não nega as diretrizes expressas no Manifesto e consubstanciadas na reforma anterior. Apenas introduz um nacionalismo estratégico, cujos efeitos na política educacional do período têm sido superdimensionados na literatura educacional" (p. 105-106).

${ }^{6}$ O artigo 13 estabelecia o seguinte: “Os programas das disciplinas serão simples, claros e flexíveis, e se comporão segundo as bases e a orientação metodológica que o Ministro da Educação e Saúde expedir". (BRASIL. Decreto-Lei n. 8.530, de 1946).

${ }^{7}$ Em relação ao currículo, o primeiro ciclo dispunha de disciplinas mais gerais em detrimento das disciplinas específicas à profissão, ou seja, apenas no último ano da formação, os alunos cursavam duas disciplinas voltadas há prática do ensinar, que eram: psicologia e pedagogia e didática e prática de ensino (artigo $7^{\circ}$ ). Já o curso de segundo ciclo apresentava seu currículo de maneira mais balanceada, articulando melhor as disciplinas gerais com as específicas à profissão, pois, desde o segundo ano, os estudos pedagógicos faziam parte da grade curricular (artigo $8^{\circ}$ ). Em ambos os ciclos, o ensino religioso e a educação moral e cívica estavam contemplados. (BRASIL. Decreto-Lei n. 8.530, de 1946).

${ }^{8}$ A predominância de professores leigos na escola primária brasileira revela uma das contradições da Lei Orgânica do Ensino Primário, que estabeleceu no Parágrafo único do artigo 21, que não seriam "admitidos em qualquer dos dois cursos candidatos maiores de vinte e cinco anos" (BRASIL. Decreto-Lei n. 8530, de 1946). Diante deste dispositivo, a maioria dos professores leigos ficou excluída de frequentar as escolas normais, pois, certamente eram maiores de 25 anos. Assim, não havia outra alternativa, se não a participação em cursos de aperfeiçoamento.

9 Outros documentos têm demonstrado a vida concomitante das duas escolas. No arquivo do Colégio Estadual Wilson Joffre encontramos um documento que traz uma relação de escolas que participariam do desfile de 7 de setembro, o qual cita as duas escolas normais, bem como, o ofício $\mathrm{n}^{\circ} 76 / 67$ enviado por Silvestre Philippi, chefe da seção de patrimônios ao Inspetor Regional de Ensino de Cascavel que tratava sobre a falta de formulários de tombamento de bens patrimoniais do Colégio Comercial, Escola Normal Colegial Irene Rickli e Escola Normal Ginasial Carola Moreira.

Recebido em: $\quad 25.04 .12$

Aprovado em: $\quad 30.05 .12$ 